\title{
Complex phenotype with social communication disorder caused by mosaic supernumerary ring chromosome 19p
}

\author{
Caroline Demily ${ }^{1,2^{*}}$, Massimiliano Rossi ${ }^{3,4}$, Gabrielle Chesnoy-Servanin ${ }^{1,2}$, Brice Martin ${ }^{2,5}$, Alice Poisson ${ }^{1,2}$, \\ Damien Sanlaville $e^{4,6}$ and Patrick Edery ${ }^{3,4}$
}

\begin{abstract}
Background: Deletions or duplications of chromosome 19 are rare and there is no previous report in the literature of a ring chromosome derived from proximal 19p. Copy Number Variants (CNVs) responsible for complex phenotypes with Social Communication Disorder (SCD), may contribute to improve knowledge about the distinction between intellectual deficiency and autism spectrum disorders.

Case presentation: We report the clinical and cytogenetic characterization of a patient (male, 33 years-old, first child of healthy Portuguese non-consanguineous parents) presenting with a complex phenotype including SCD without intellectual deficiency and carrying a mosaic supernumerary ring chromosome 19p. Microarray-Based Comparative Genomic Hybridization and Fluorescence in situ Hybridization were performed. Genetic analysis showed a large mosaic interstitial duplication 19p13.12p12 of the short arm of chromosome 19, spanning $8.35 \mathrm{Mb}$. Our data suggested a putative association between psychosocial dysfunction and mosaic pure trisomy 19p13.2p12.

Conclusion: This clinical report demonstrated the need to analyze more discreet trait-based subsets of complex phenotypes to improve the ability to detect genetic effects. To address this question and the broader issue of deciphering the yet unknown genetic contributors to complex phenotype with SCD, we suggest performing systematic psychological and psychiatric assessments in patients with chromosomal abnormalities.
\end{abstract}

Keywords: Genetics, Autism, Social communication disorder, Duplication, Neurodevelopment, Chromosomal abnormalities, Trisomy, Copy number variants

\section{Background}

Deletions or duplications of chromosome 19 are rare and there is no previous report in the literature of a ring chromosome derived from proximal 19p. We report the clinical and cytogenetic characterization of a patient presenting with several abnormalities including Social Communication Disorder (SCD) without Intellectual Deficiency. This patient presented a complex phenotype with neurocognitive features, dysmorphism, growth delay and SCD. He was carrying a mosaic pure trisomy 19p13.2p12.

\footnotetext{
* Correspondence: caroline.demily@ch-le-vinatier.fr

${ }^{1}$ Centre de dpistage et de prises en charge des troubles psychiatriques d origine gntique, Ple Ouest, Centre Hospitalier le Vinatier, 95 bld Pinel, 69677 Bron cedex, France

${ }^{2}$ Centre de Neuroscience Cognitive, UMR 5229 (CNRS et Universit Lyon 1), Lyon, France

Full list of author information is available at the end of the article
}

Pathogenic copy number variants (CNVs) are found in nearly $20 \%$ of individuals with Intellectual Deficiency (ID) [1] and in $10 \%$ of patients showing Autism Spectrum Disorders (ASD) [2]. Nevertheless, the relevance of making a clinical distinction between ID and ASD in terms of genetic etiology remains controversial because of considerable overlaps of the causative genes or chromosomal regions. Copy Number Variants (CNVs) responsible for complex phenotype with Social Communication Disorder (SCD), a diagnosis related to ASD, may contribute to improve knowledge about this data.

\section{Case presentation}

\section{Clinical report}

The patient was the first child of healthy Portuguese nonconsanguineous parents. The fathers height was $163 \mathrm{~cm}$ 
and the mothers was $148 \mathrm{~cm}$. Family history was otherwise unremarkable. Pregnancy and delivery were normal: birth weight was $2.550 \mathrm{~kg}$, at -2 standard deviations (SD); birth length was $46 \mathrm{~cm}(-3 \mathrm{SD})$; head circumference: $32 \mathrm{~cm}(-3 \mathrm{SD})$, Apgar score was 10, at 1 and $5 \mathrm{~min}$. Short stature of prenatal onset was noted.

During infancy, he showed gastro-esophageal reflux and recurrent otitis media. He underwent surgical interventions for inguinal hernias, adenoidectomy and umbilical cyst ablation.

He had mild motor delay and started walking at the age of 2 years. He subsequently showed moderate learning difficulties. He has undergone several trainings in electricity and computing, but to no avail. He has had various odd jobs (e.g. waiter, fast food employee) and currently lives on his own.

He was referred to our department at the age of 33 years. Clinical data showed that he was $152 \mathrm{~cm}$ tall $(-3,5 \mathrm{SD})$ and weighed $43.9 \mathrm{~kg}$; body mass index was normal $\left(18.9 \mathrm{~kg} / \mathrm{m}^{2}\right)$ as well as head circumference $(55 \mathrm{~cm})$. He had a long face, high forehead, thick eyebrows, down-slanting palpebral fissures, a prominent nose with high nasal bridge and malar hypoplasia (Figure 1a and b). He had a mild scoliosis (Figure 1c) and neurological examination was normal.

He presented a psychiatric phenotype. He presented difficulties in acquiring/using language, limited effective communication and social relationships. A social communication disorder was diagnosed according to DSM5 criteria. The neuropsychological evaluation documented a normal intellectual functioning (total IQ: 90). The patient showed decreased psychomotor speed impacting on attentional tasks and mildly impaired verbal memory. However, he had good executive functioning and visual memory abilities.

Complete diagnostic assessment, including fragile $\mathrm{X}$ molecular analysis, full blood count, ammonia, plasma amino acids, urine orotic acid, screening for creatine metabolism deficiencies and urinary organic acids, was normal. Magnetic resonance imaging of the brain was normal. Skeletal survey showed mild scoliosis with no obvious sign of bone dysplasia. Echocardiography was normal and abdominal ultrasounds scan showed isolated mild hepatomegaly; liver function tests were normal.

\section{Cytogenetic analysis}

Genomic analyses were performed after obtaining a signed informed consent, according to French legislation. Those analyses are performed routinely and do not need specific ethical approval by a committee.

\section{Chromosome analysis}

Conventional blood lymphocytes karyotypes (both GTG and RHG-banding) were performed according to standard methods.

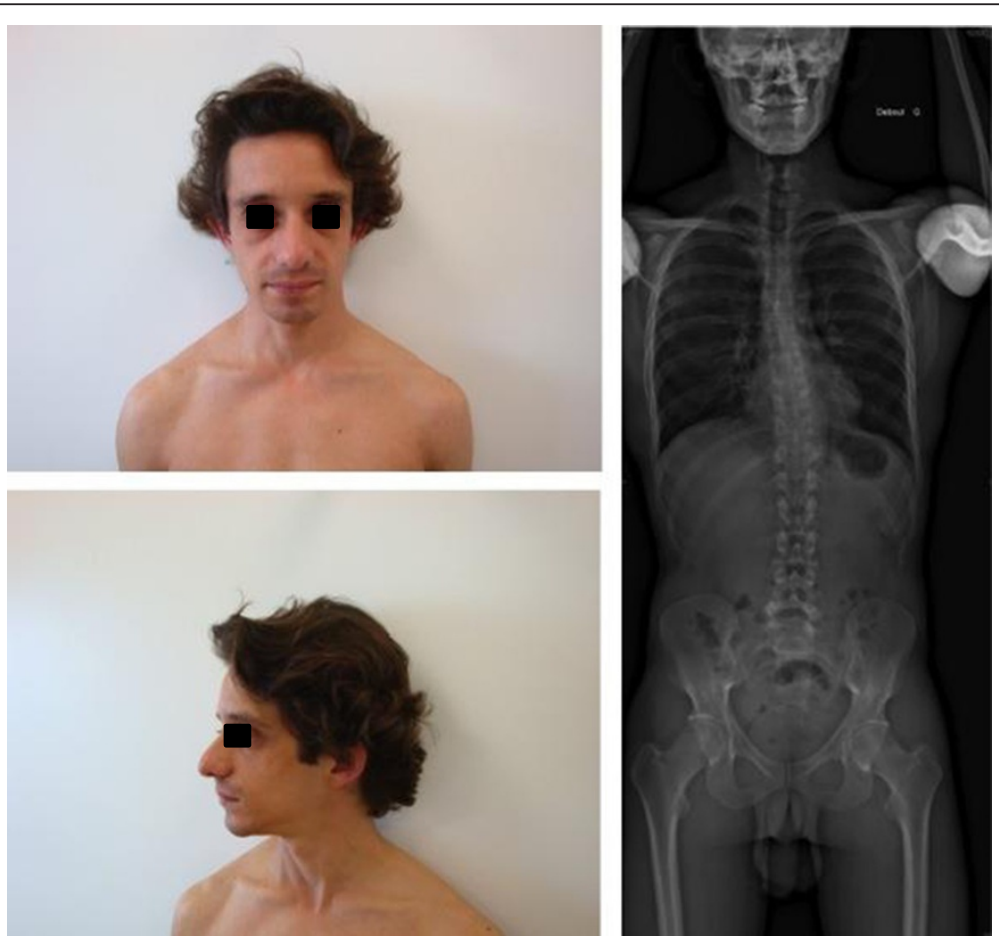

Figure 1 Facial dysmorphism of patient (a face and b profile) and X-Rays showing the scoliosis (c). 


\section{Microarray-Based Comparative Genomic Hybridization (aCGH)}

Genomic DNA extraction and aCGH were performed as previously described, with an 180,000-oligonucleotide (180 K) microarray (Sure Print G3 Human CGH Microarray Kit, Agilent Technologies, Santa Clara, CA) [3]. The presence of a copy number variation was considered when at least three contiguous oligonucleotides showed an abnormal $\log 2$ ratio. Array-CGH results were analyzed using the UCSC hg19 assembly. The average gain of $\log 2$ ratio was calculated, for each dyeswap experiment (two results for each patient) and the level of mosaicism was also calculated [4].

\section{Fluorescence In Situ Hybridization (FISH)}

FISH was performed with the BAC clone CTD-2332E1 located in 19p12 (chr19:20,794,365-20,798,195 bp, hg19). The probe was FITC-labelled by nick-translation, as previously described [3] and hybridized on metaphase spread, together with the 19qter control probe (Cytocell, Cambridge, UK).

\section{Results}

Blood standard karyotype showed the presence of a small supernumerary marker chromosome (sSMCs). This marker was present in $72 \%$ of examined cells (18/25). aCGH showed a large mosaic interstitial duplication of the short arm of chromosome 19, spanning 8.35 Mb :arr[hg19] 19p13.12p12(15,987,511-24,340,741)x2 3 (Figure 2). The level of mosaicism was evaluated at $55 \%$.

FISH confirmed the presence of the sSMCS in $50 \%$ of examined cells (40/70 metaphase cells and 44/100 nucleic cells) and allowed us to conclude that this sSMCs was a ring of chromosome 19 encompassing only a part of the $19 \mathrm{p}$ genomic region. FISH analysis, performed in both parents, was normal, thus confirming the de novo origin of the ring chromosome 19 observed in the patient.

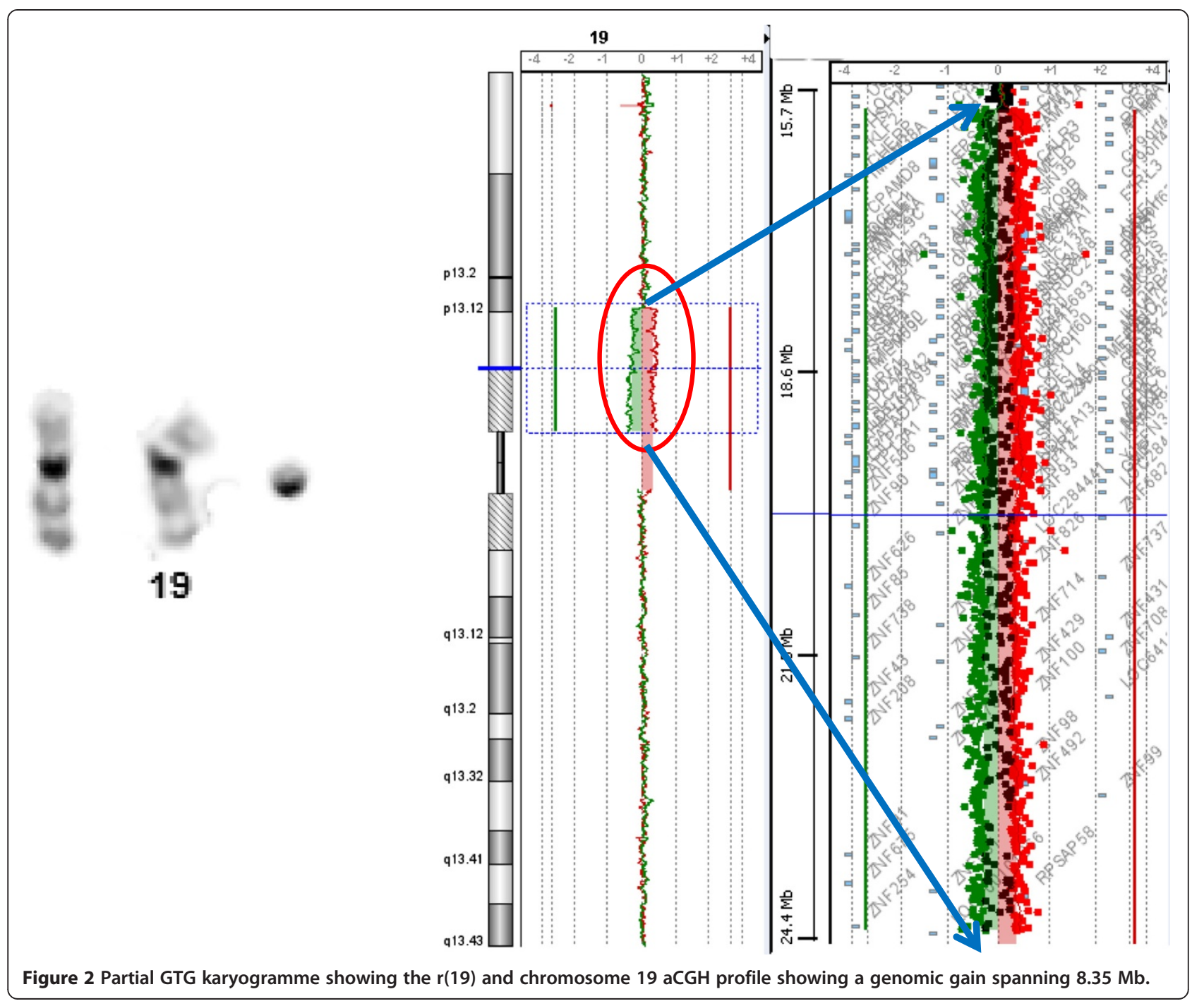




\section{Discussion}

Analysis of genomic rearrangements using aCGH in patients with various symptoms including psychiatric features exposes unexpected complexity. First of all, social communication disorder in people with chromosomal abnormalities may be much more common than reported because psychological or psychiatric assessments are not systematically carried out.

Moreover, molecular studies are usually performed for ID, ASD and/or syndromes of multiple congenital abnormalities. The genetic background of ASD is highly heterogeneous and the fact of having most common or rare CNVs may usually not be considered as a unique cause, but may occasionally increase the risk of developing ASD. Recently, Pinto et al. [5], showed that rare CNVs are an important source of risk for ASD. Also, a genome-wide screen for autism loci identified the best compatibility with linkage to $17 \mathrm{q} 11.2$ and $19 \mathrm{p} 13$, with maximum multipoint heterogeneity LOD scores of 2.9 and 2.6, respectively [6]. The mosaic gain identified with aCGH in our patient encompasses 398 genes including 97 OMIM genes and 13 morbid OMIM genes, namely CRFL1, RFXANK, IL2RB1, MYO9B, JAK3, SLC5A5, COM, GDF1, GTPBP13, NDUFA13, INSL3, PIK3R2, and CALR3.

To our knowledge, only 9 cases with extra ring $19 \mathrm{chr}$ were reported [7]. The short arm of chromosome 19 only was involved using either FISH or aCGH in two of these cases. Both patients had cerebral abnormalities including respectively enlarged cerebral ventricles and cortical atrophy [8] and Dandy Walker malformation [8]. Among these cases, only case number $19-\mathrm{W}-\mathrm{p} 12 / 2-1$ is suitable for comparison, because the sSMC was studied by aCGH and the genomic region included $2.53 \mathrm{Mb}$ of the $19 \mathrm{p}$ pericentromeric region. This patient showed hip subluxation, pes calcaneovalgus congenitus, periodic breathing, congenital stridor and feeding problems. At 3 months of age, an extreme restlessness, nearly opisthotonos and at 5 months of age hyperexcitability, and developmental delay were noted. Unfortunately, social communication was not described. In Liehrs database (http://ssmc-tl. com/sSMC.html), 43 sSMC derived from the chromosome 19 were reported and 70\% have clinical features. The polymorphic region proposed by Liehr spanned from 15.2 Mb to $39.08 \mathrm{Mb}$ genomic positions, thus including the duplicated genomic region identified here. However, social cognitive aspects of individuals considered as asymptomatic with a $\mathrm{CNV}$ of this genomic region were not studied in detail.

\section{Conclusion}

This clinical report suggests 19p13.12p12 as a possible SCD susceptibility locus and demonstrates the need to analyze more discreet trait-based subsets of complex phenotypes to improve the ability to detect genetic effects. To address this question and the broader issue of deciphering the yet unknown genetic contributors to complex phenotype with SCD, we suggest performing psychological and psychiatric assessments in patients with chromosomal abnormalities.

\section{Consent}

Written informed consent was obtained from the patient for publication of their individual details and accompanying images in this manuscript. The consent form is held in the patients clinical notes and is available for review by the Editor-in-Chief.

\section{Abbreviations}

SCD: Social communication disorder; ASD: Autism spectrum disorder; CNVs: Copy number variants; ID: Intellectual deficiency; DSM-5: Diagnostic and statistical manual Fifth revision; SD: Standard Deviation; FISH: Fluorescence In Situ Hybridization; aCGH: Microarray-based comparative genomic hybridization.

\section{Competing interests}

The authors declare that they have no competing interests

\section{Authors contributions}

$C D, M R$, DS and PE designed the report. MR, AP and BM collected the clinical data. DS performed the cytogenetic analyses. GCS performed the neuropsychological assessment. CD, MS, DS and PE analysed the data and wrote the paper. All authors read and approved the final manuscript.

\section{Acknowledgements}

Nicolas Franck for giving some advices \& the Conseil Scientifique de la Recherche du Vinatier.

\section{Author details}

${ }^{1}$ Centre de dpistage et de prises en charge des troubles psychiatriques d origine gntique, Ple Ouest, Centre Hospitalier le Vinatier, 95 bld Pinel, 69677 Bron cedex, France. ${ }^{2}$ Centre de Neuroscience Cognitive, UMR 5229 (CNRS et Universit Lyon 1), Lyon, France. ${ }^{3}$ Hospices Civils de Lyon, service de gntique et centre de rfrence des anomalies du dveloppement, GHE, Lyon, France. ${ }^{4}$ Centre de Recherche en Neurosciences de Lyon, Inserm U1028, UMR CNRS 5292, Universit Claude Bernard Lyon 1, Lyon, France. ${ }^{5}$ Service Universitaire de Rhabilitation, Centre Hospitalier le Vinatier, Bron, France. ${ }^{6}$ Hospices Civils de Lyon, service de gntique, centre de rfrence des anomalies du dveloppement, laboratoire de cytogntique, GHE, Lyon, France.

\section{Received: 21 July 2014 Accepted: 2 December 2014}

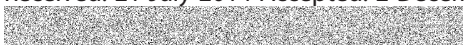

\section{References}

1. Kaminsky EB, Kaul V, Paschall J, Church DM, Bunke B, Kunig D, Moreno-De-Luca D, Moreno-De-Luca A, Mulle JG, Warren ST, Richard G, Compton JG, Fuller AE, Gliem TJ, Huang S, Collinson MN, Beal SJ, Ackley T, Pickering DL, Golden DM, Aston E, Whitby H, Shetty S, Rossi MR, Rudd MK, South ST, Brothman AR, Sanger WG, lyer RK, Crolla JA, et al: An evidence-based approach to establish the functional and clinical significance of CNVs in intellectual and developmental disabilities. Genet Med 2011, 13:777 784.

2. Sanders SJ, Ercan-Sencicek AG, Hus V, Rui L, Murtha MT, Moreno-De-Luca D, Chu SH, Moreau MP, Gupta AR, Thomson SA, Mason CE, Bilguvar K, Celestino-Soper PBS, Choi ML, Crawford EL, Davis L, Davis Wright NR, Dhodapkar RM, DiCola M, DiLullo NM, Fernandez TV, Fielding-Singh V, Fishman DO, Frahm S, Garagaloyan R, Goh GS, Kammela S, Klei L, Lowe JK, Lund SC, et al: Multiple recurent de novo copy number variations (CNVs) including duplications of the 7q11.23 Williams-Beuren syndrome region are strongly associated with autism. Neuron 2011, 70:863 885

3. Schluth-Bolard C, Delobel B, Sanlaville D, Boute O, Cuisset JM, Sukno S, Labalme A, Duban-Bedu B, Plessis G, Jaillard S, Dubourg C, Henry C, Lucas J, Odent S, Pasquier L, Copin H, Latour P, Cordier MP, Nadeau G, Till M, Edery $P$, Andrieux J: Cryptic genomic imbalances in de novo and inherited 
apparently balanced chromosomal rearrangements: array CGH study of 47 unrelated cases. Am J Med Genet A 2009, 149A:2584 2587.

4. Valli R, Marletta C, Pressato B, Montalbano G, Lo Curto F, Pasquali F, Maserati E: Comparative genomic hybridization on microarray (a-CGH) in constitutional and acquired mosaicism may detect as low as $8 \%$ abnormal cells. Mol Cytogenet 2011, 9:4 13.

5. Pinto D, Delaby E, Merico D, Barbosa M, Merikangas A, Klei L, Thiruvahindrapuram B, Xu X, Ziman R, Wang Z, Vorstman JA, Thompson A, Regan R, Pilorge M, Pellecchia G, Pagnamenta AT, Oliveira B, Marshall CR, Magalhaes TR, Lowe JK, Howe JL, Griswold AJ, Gilbert J, Duketis E,

Dombroski BA, De Jonge MV, Cuccaro M, Crawford EL, Correia CT, Conroy J, et al: Convergence of genes and cellular pathways dysregulated in autism spectrum disorders. Am J Hum Genet 2014, 94:677 679.

6. McCauley JL, Li C, Jiang L, Olson LM, Crockett G, Gainer K, Folstein SE, Haines JL, Sutcliffe JS: Genome-wide and Ordered-Subset linkage analyses provide support for autism loci on 17q and 19p with evidence of phenotypic and interlocus genetic correlates. BMC Med Genet 2005, 6:1.

7. Melis D, Genesio R, Del Giudice E, Taurisano R, Mormile A, D Elia F, Conti A, Imperati F, Andria G, Nitsch L: Selective cognitive impairment and tall stature due to chromosome 19 supernumerary ring. Clin Dysmorphol 2012, 21:27 32 .

8. Novelli A, Ceccarini C, Bernardini L, Zuccarello D, Digilio MC, Mingarelli R, Dallapicolla B: Pure trisomy $19 p$ in an infant with an extra ring chromosome. Cytogenet Genome Res 2005, 111:182 185.

doi:10.1186/s12881-014-0132-3

Cite this article as: Demily et al: Complex phenotype with social communication disorder caused by mosaic supernumerary ring chromosome 19p. BMC Medical Genetics 2014 15:132.

\section{Submit your next manuscript to BioMed Central and take full advantage of:}

$\bowtie$ Convenient online submission

$\otimes$ Thorough peer review

$\nabla$ No space constraints or color $\nabla$ gure charges

$\otimes I m m e d i a t e$ publication on acceptance

$\triangle$ Inclusion in PubMed, CAS, Scopus and Google Scholar

$\otimes$ Research which is freely available for redistribution 